\title{
Kpamkue сообиения
}

У, К 5 -

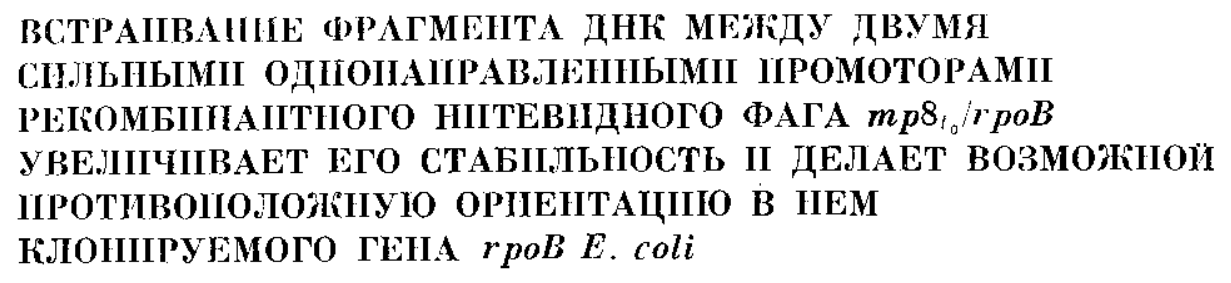

Е. Б. Іатон, А. Н. Живолуп

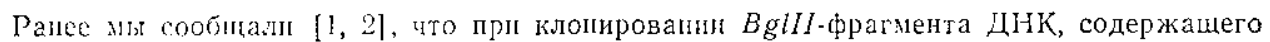

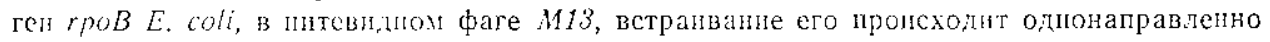
ж ирпводшт к образованшю нестабильных рекомбинаптыш фагов. Предполагалось, что :рицщой неспбнльпости и однонаправленности могло быть палиние двух силыных про-

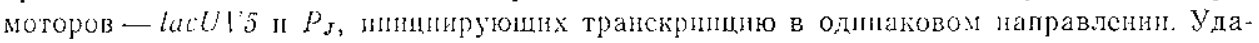

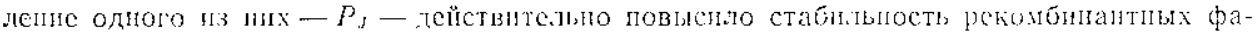

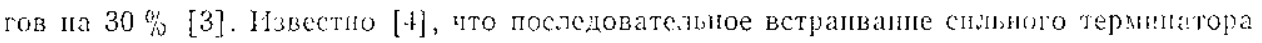

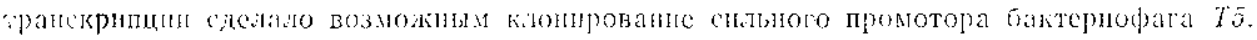

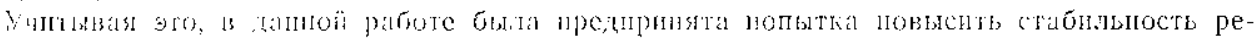

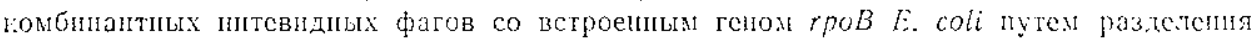

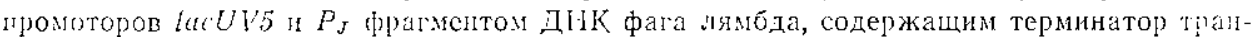

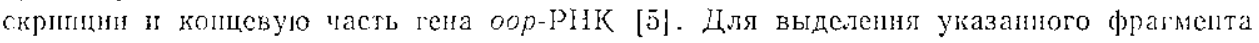

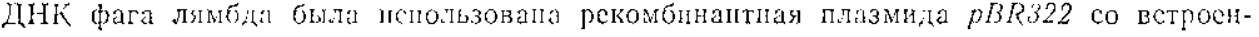

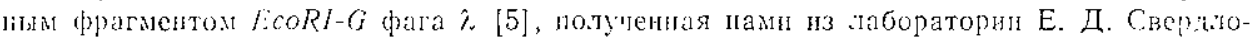

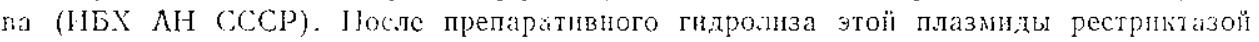
licoRI pparмcuт EcoR/-G выделялы путем электрофореза в 0,8\%-ном агарозном геле, адсороиии па полоску Whatman DE 81 и послелующей элюции с нее, как описано в [6].

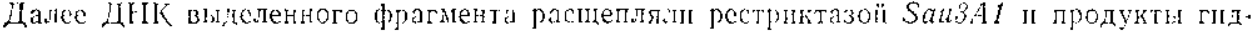

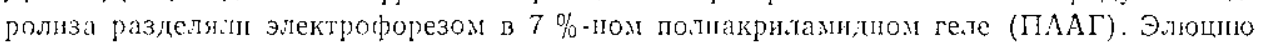

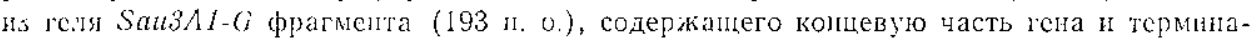
төр трапскрипции оор-РНК фага лямбда, проводияи, как указано в [7]. Лля встраивашия выпеуказапного Sal3A1-фрагмента в репликативную dорму (РФ) фага M/3mp8

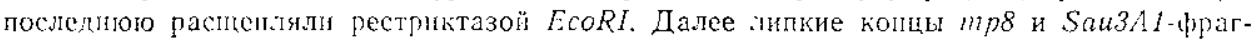

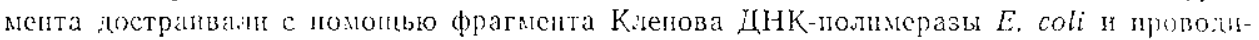

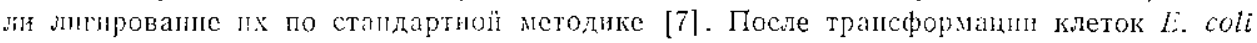
$71-18$ [8] алпквотамы лигазной смеси клоны, содержапие рекомбинантице фаговые DHK, отбирали путем гиоридизации с радиоаппвым зондом. Қлетки E. coli из образовавишіхся в результате трансформацин фаговых блянек переноспли па чашки с LB [8] aгаром, а затем на нитроцелполозные фильтры BA 85/23 фнрмы «sclsleicher \& Schüll», ФРГ. В качествс радиоактивного зонда использовалы плазмиду $p B R 322$ со встросиным FcoR $I$-фрагментом фага $\lambda$. Введсние радиоактивиой метки проводили с номонцю реакци ник-трапсляцин, используя стандартиые растворы, ДНК-полимеразу и

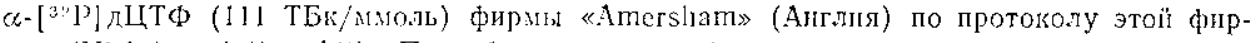
мы (Nick-transtation kit). Прегибрпдизацию, гибридизацию с радноктивным зондом (106 имг мин $^{-1} \cdot$ мкг $^{-1}$ ипуубационной смеси) осуществляли при $42^{\circ} \mathrm{C}$ в течение 18 ч. (рлысты отмывалі при $68^{\circ} \mathrm{C}$. Вынеуказаныс процедуры проводили, как указано в [7].

I10 результатам гібридлзации было отобрано два клона $E$. coll, обладающих полюжительпым сигіалом. Для подтверждсппя наличия клопированного Sau3A1-фрагмента РФ фаговой ДНК, выделенную из әтих клонов, расшепляли рестриказой PлиI и 


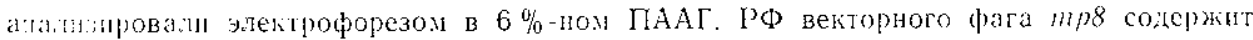

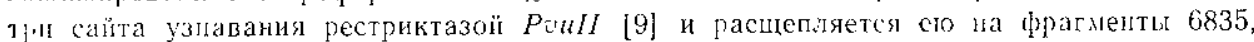

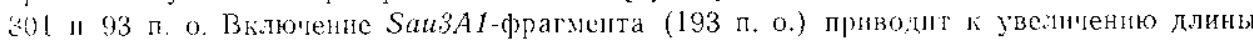

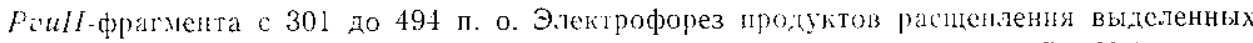

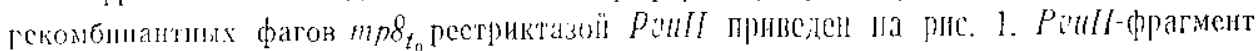

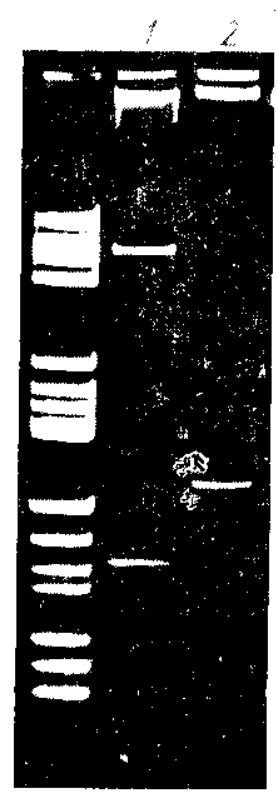

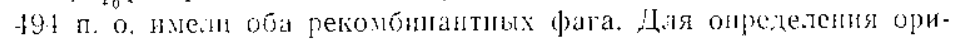

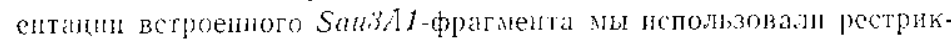

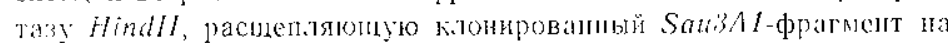

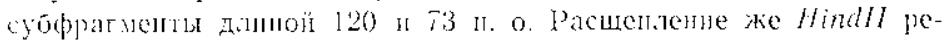

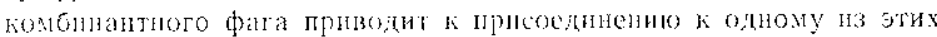

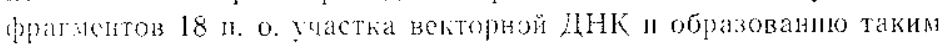

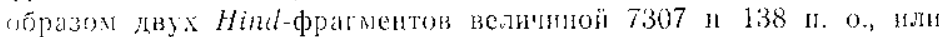

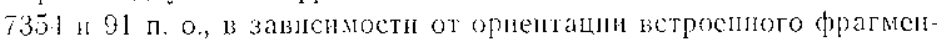

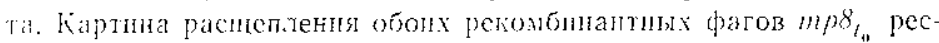

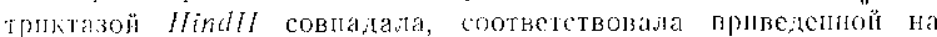

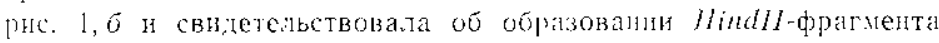

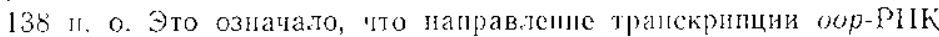

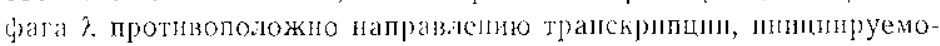

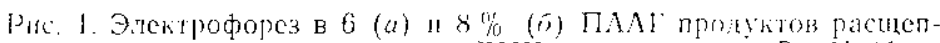

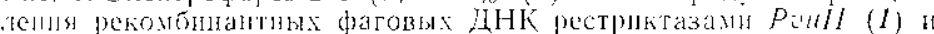

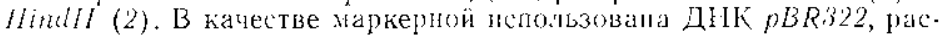

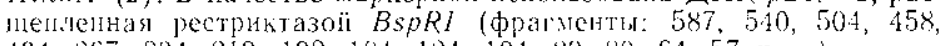
$431,267,231,213,192,181,124,104,89,80,61,57$ 11. o).

Fig. 1. Electrophoresis in $6 \%$ (a) and $8 \%$ (6) $\mathrm{PAAG}$ of Paull (1) and Hindll (2) cleaver recombinant phage DNAs. BspRI-digested pBR322 was used as a marker (fragmenis: 587, 540, 504, $458,434,267,23.1,213,192,184,124,104,89,80,64,57 \mathrm{bp})$.

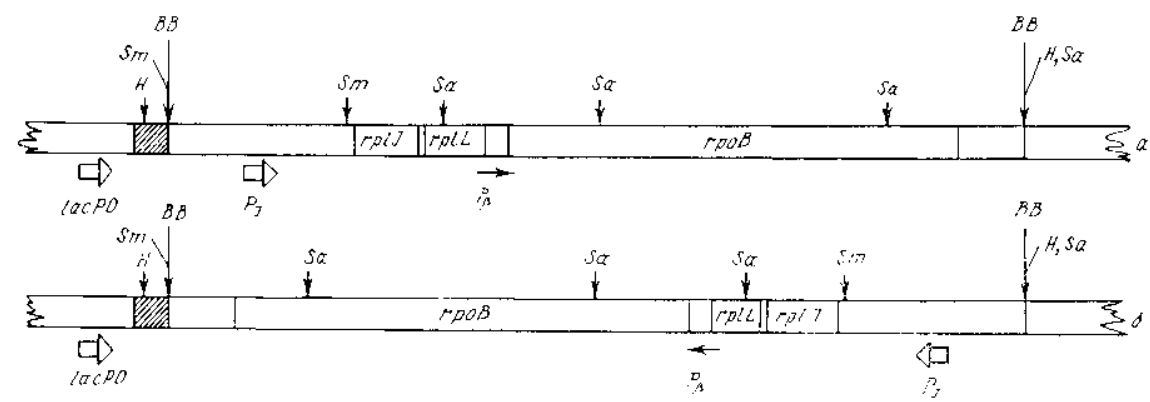

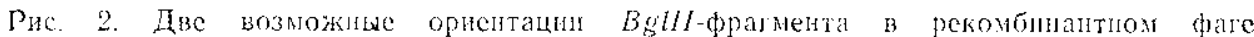

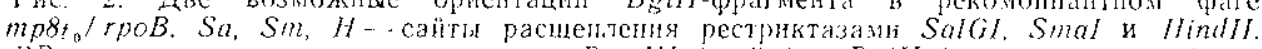

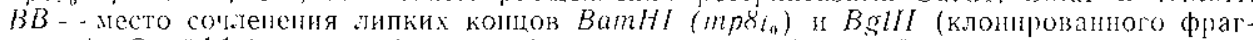
мента). SаизА1-фрагмент фага лямбда, клонированный в пр 8 , замтрнхован.

Jig. 2. Two possible orientations of the $B g / / /$ fragment in recombinant mps $t_{v} / r p o B$ phage. Sa, Sm, II -- sites of SalGl, Smal and /Tindll digestion. BB .... a site of conjuction of

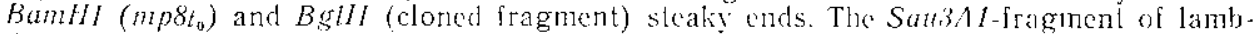
da phage cloned into mp 8 is hatched.

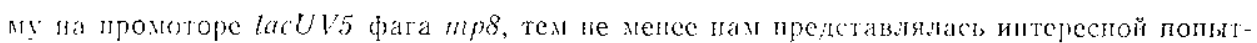

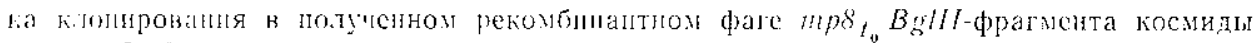

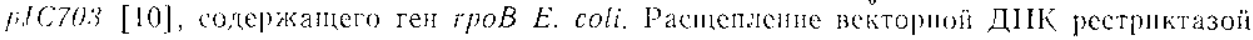

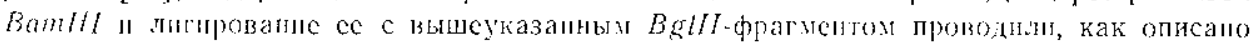

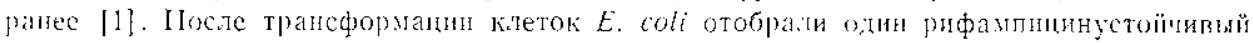

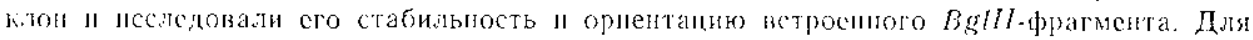

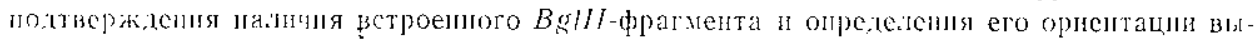

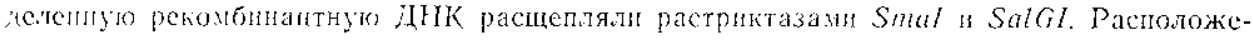

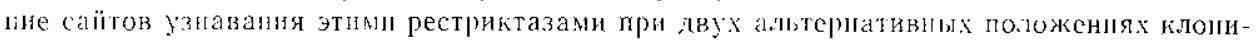

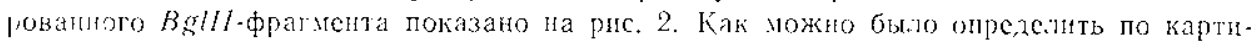
lе элсктрфореза в 1 \%-ном агарозном геле иролуктов расцепјення Smal, паблюда:

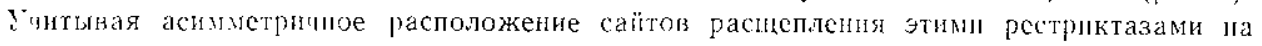




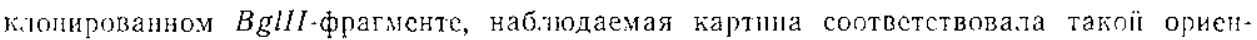
тацик, при которой иаправление трапскрипции, пнициируемой па промоторах lacU V5 и $P_{J}$, противоположно.

Определение сгабильости скопструированного рекомбинантного фага, проведеп1:ое, как описано ранее [1], показано, что опа возросла до $93 \%$.

Таким образом, копструирование реконбинаптного питевид-

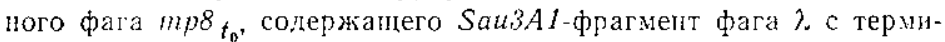
ғатором транскрипци оор-РНК, и пос.те,ующее к:Іонирование в нем $B g l l /$-фрагмента $p / C 70.3$, включаюшего ген $r p o B$, позво.лио повысить стабилыгость рекомбинаптных фагов $m p \varepsilon_{t_{0}} / r p o B$ и встронть указанный $B g l l /$-фрагмснт в орнентаци, противололожшой наблюдасмой ранее. Оба обпаружених факта согтасуютея $\mathrm{c}$ предположением о влиянин двух силыпых однопаправлепшх промоторов на стабильность рекомбинаптных фагов и ориентанию в ннх к.лонруемого $B g l l /$-фрагмента.

Рис. 3. Электрофорез в $1 \%$-ном агарозном геле продуктов рас-

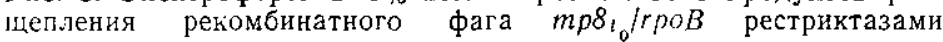
SulGI (1) и SmaI (2). В качестве маркера использована космида pJC703, (3), расщепленная рестриктазой EcoRI (фрагменты: 7,0; 4,$2 ; 1,82 ; 1,5 ; 1,35 ; 0,75$ и $0,69 \mathrm{M}$ д).

Fig. 3. I \% agarose gel electrophoresis of SalGI (1) and SmaI (2) digcsted recombinant phase mp8to/rpoB. pJC703 cosmid cleaved by EcoRI (fragments: $7.0,4.2,1.82,1.5,1.35,0.75,0.69 \mathrm{Md}$ ) was used as a marker (3).

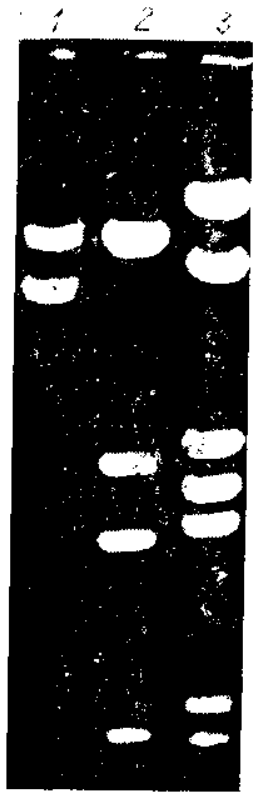

\section{INSERTION OF A DNA FRAGMENT BETWEEN TWO STRONG SIMILARLY ORIENTED PROMOTERS OF RECOMBINANT FILAMENTOUS PHAGE $m p s_{t} / r p O B$ INCREASES ITS STABILITY AND MAKES POSSIBLE AN OPPOSITE ORIENTATION OF THE CLONED E. coli $r p o B$ GENE}

\section{E. B. Paton, A. N. Zhivolup}

Institute of Molecular Biology and Genetics,

Academy of Sciences of the Lkrainian SSR, Kiev

Sum m a r y

$\Lambda$ fragment of $\lambda$ phage DNA containing terminator of transcription $\left(t_{0}\right)$ and terminal part of the oop-RNA gene was inserted into the polylinker area of $M 13$ mp 8 filamentous phage. The obtained phage was used to clone a BgllI fragment of pJC703 cosmid, contairsing $E$. coli genes $r p I J, r p I L$ and $r p o B$ together with promoters $P_{J}$ and $P_{\beta}$. Stability of the obtained $m p 8_{t_{0}} / r p o B$ recombinant phages increased up to $93 \%$ and an orientation of the cloned $B g l I I$-fragment opposite to the previously observed one became possibie.

1. Патон Е. Б., Видиаска М. Н., Свердлов Е. Д. Одионаправлениая ориентация гена

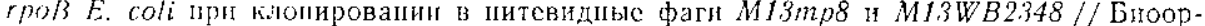
Ган. химия. $-1984 .-10$, № $11 .-$ C. 1544-1547.

2. Патон Е. Б., Вудласка М. Н., Свердлов Е. Д. Однопаправленная ориентация гена $r$ poB $E$. coli, клонированного в иитевидные фаги $M 1.3 / /$ Макромолекулы в фупкциоиирующей клетке : Тез. докл. IV симпоз. СССР - Италия. - Киев, 1984. - С. 89.

3. Патон Е. Б., Виднаска М. Н., Свердлов Е. Д. Присутствие собетвенпого промотора гров-гена спижает стабилыпость рекомбинантных одпонитевых фагов, содержащих этот ген // Биополимеры и клетка. - 1985.-1, № 3. - С. 160-162.

4. Cloning and analysis of strong promoters is made possible by the downstream placement of a RNA termination signal / R. Crent2, A. Langner, A. C. Y. Chang et al. /I Proc. Nat. Acad. Sci. USA. - 1981. -78, N 8. - P. 4936-4940.

5. Primary structure of an EcoRI fragment of $\lambda \mathrm{imm} 434$ DNA containing regions cI-cro of phage 4:34 and $c I l-o$ of phage lambda/Yu. A. Ovchinnikov, S. O. Guryev, A. S. Krayev et al. // Genc. - 1979.-6, N 2. - P. 235-249.

6. A reliable method for the recovery of DNA fragments from agarose and acrylamide 
gels / I. Dretgen, M. Bellard, P. Sassone-Corsi, P. Chambon // AnaI. Biochem.- 1981.112. N 2. - P. $295-298$.

7. Maniatis T. Fritsch E. F. Sambrook J. Molecular cloning - a laboratory manual. Vew York: Cold Spring Harbor, 1982,--545 p.

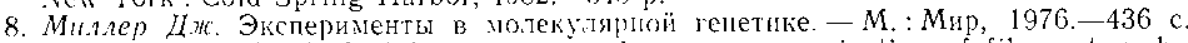

9. Beck E., Zink B. Nucleotide sequence and genome organization of filamentous bacteriophages $f l$ and $f d / /$ Gene. -- $1981 .--16, N 1$. - P. 35-58.

10. Collins J. Deletions, insertions and rearrangements affecting rpoB gene expression // Mol. and Gen. Genel. - 1979.-173, N 1.-P. $217--220$.

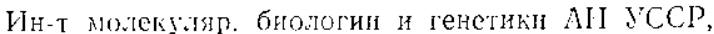

IIo.1yчe!10 15.02 .86 Киев

19. Ochi K. Protoplast fusion//Molecular breeding and genelics of applied nijernorganioms / Eds K. Sakaguedi, M. Okanisli. ... New York Acad press, 1980 .... P 88-94

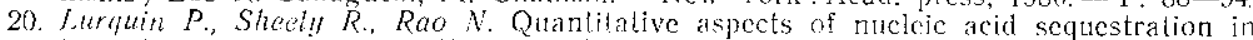
large liposomes and their effects on plant protoplast// FEBS lett. - 1981. -25 , N 2. P. $183--187$.

21. Weisman G., Cohen C., Hoffstein S. Introduction of enzymes by means of liposones,

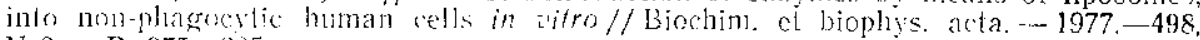
N 2. - P. $375-.385$

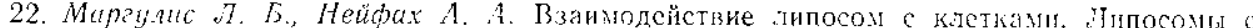

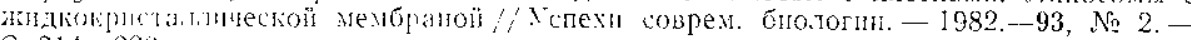
C. $21 !-229$

Нн-т у!кробиміогын и вирусотогин

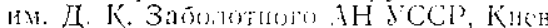

Потутено 22.07 .85 